\title{
Is symptom burden a predictor of anxiety and depression in patients with cancer about to commence chemotherapy?
}

\author{
Sibilah J Breen, Carl M Baravelli, Penelope E Schofield, Michael Jefford, Patsy M Yates and Sanchia K Aranda
}

$\mathrm{H}$ igh levels of psychiatric morbidity, distress and symptom burden are commonly reported by cancer patients, including those undergoing chemotherapy. ${ }^{1-4}$ Recognition and treatment of mood disorders such as depression are important because, untreated, they may lead to difficulties in patient management and symptom control, increased hospital stays, and decreased adherence to and acceptance of treatment. ${ }^{5-9}$ Studies have shown significant relationships between burden from physical symptoms and depression, ${ }^{10,11}$ but the relationship with anxiety is less clear. ${ }^{12}$ The evaluation of symptom burden in the literature is made difficult by variations in definition and measurement. ${ }^{4,11,13}$

While symptom burden, anxiety and depression may be high in patients undergoing chemotherapy, only two studies have specifically considered the pre-chemotherapy setting. One study found that $48 \%$ of patients with early breast cancer who were commencing chemotherapy had significant anxiety, ${ }^{14}$ while the second found that $27 \%$ of hospitalised patients with various cancers commencing chemotherapy reported depression. ${ }^{15}$ A further study reported that the total number of symptoms, tiredness and perceived functional impairment were all independently associated with an increased likelihood of depression in patients with lung cancer who were commencing treatment with either chemotherapy or radiotherapy. ${ }^{11}$ It is therefore important to consider both physical and emotional factors before treatment is commenced, as the subsequent administration of chemotherapy drugs is likely to increase symptom burden and associated psychological distress.

In this study, we assessed the prevalence of anxiety, depression and physical symptoms in a mixed population of patients with cancer before their first ever chemotherapy treatment. As symptoms are rarely observed to occur alone, but rather in clusters, ${ }^{4}$ we also explored the presence of distinct sets of symptoms. Finally, we investigated the relationship between patient symptom distress ("bother") and both anxiety and depression. We chose to investigate symptom distress because previous studies have indicated that

\section{ABSTRACT}

Objectives: To assess the prevalence, severity and distress from physical symptoms and the prevalence of anxiety and depression in patients about to undergo chemotherapy for potentially curable cancers; and to explore the presence of symptom clusters and investigate their relationships with anxiety and depression.

Design, participants and setting: Cross-sectional survey of 192 patients with breast or gastrointestinal cancers or lymphoma before first ever chemotherapy treatment with curative intent.

Main outcome measures: Hospital Anxiety and Depression Scale to assess anxiety and depression and the Chemotherapy Symptom Assessment Scale to measure physical symptom prevalence, severity and distress ("bother").

Results: Prevalence of anxiety was $45 \%$ and depression $25 \%$. The most prevalent physical symptoms were pain (48\%), feeling unusually tired (45\%) and difficulty sleeping (45\%). Physical symptoms rated as most severe were pain (28\%), difficulty sleeping (26\%) and feeling unusually tired (19\%). Physical symptoms causing the most distress were pain $(39 \%)$, constipation (18\%) and nausea (16\%). Factor analysis of symptom distress scores indicated that five factors explained $36.7 \%$ of the variance and included: gastrointestinal (nausea, vomiting, pain), general malaise (tiredness, feeling weak, headaches), emotional (feeling depressed, feeling anxious), nutritional (changes to appetite, weight loss or gain) and general physical (mouth/throat problems, shortness of breath).

Regression analysis indicated that symptom distress for the malaise $(\beta=1.46 ; P<0.001)$, nutritional $(\beta=0.70 ; P<0.05)$ and gastrointestinal $(\beta=0.73 ; P<0.05)$ factors were independent predictors of depression.

Conclusions: Before commencing chemotherapy, patients are already experiencing distressing symptoms and have high scores for anxiety and depression, partially explained by physical symptom distress. Patients should be routinely screened for both emotional and physical needs and appropriate interventions should be developed.

Trial registration: Australian New Zealand Clinical Trials Registry ACTRN012606000178549.

MJA 2009; 190: S99-S104

the same symptom may not be equally distressing to all patients, and that different symptoms affect patients' quality of life to different extents. ${ }^{16,17}$

\section{METHODS}

In this study, we report baseline data from a randomised controlled trial testing a psychoeducational intervention for patients before receiving chemotherapy. The study was conducted at the Peter MacCallum Cancer Centre in Melbourne, Victoria, with ethics approval from the centre's ethics committee. Eligibility criteria included: histopathological confirmation of potentially curable breast cancer, lymphoma or any cancer of the gastrointestinal (GI) tract; age over 18 years; a grade of $\leqslant 2$ on the Eastern Cooperative Oncology Group (ECOG) performance status scale; about to receive first ever chemotherapy treatment; and ability to communicate and read English. Patients were excluded if they had a known cognitive deficit.

Eligible patients were approached after their decision to have chemotherapy and were informed about the study. Patients provided written consent before completing a battery of self-report measures.

\section{Measures}

- Demographic and clinical characteristics: clinical data obtained included diagnosis, disease stage, ECOG performance status, and history of previous cancer treatment (ie, surgery or radiotherapy). Demographic data collected included sex, age, marital status, employment status, and first language spoken. 
- Anxiety and depression: these were assessed using the 14-item Hospital Anxiety and Depression Scale (HADS) ${ }^{18}$ The HADS contains two subscales (one for anxiety and one for depression), each comprising seven items. Subscale scores are reliable and valid measures of anxiety and depression, and the HADS has been validated in the cancer context. ${ }^{19,20}$ Subscale scores range from zero to 21 , with scores of 8 to 10 indicating probable subclinical cases of anxiety or depression, while scores of 11 or higher indicate clinical cases. ${ }^{18}$

- Physical symptoms: the Chemotherapy Symptom Assessment Scale (C-SAS) was used to measure symptom incidence, symptom severity and symptom distress (bother). The C-SAS is a 24-item self-report scale developed for clinical assessment of common cancer symptoms in outpatient facilities. ${ }^{17}$ The advantage of the C-SAS is that it provides a patient-centred account of symptom experiences, including the psychological domain of bother to measure symptom distress. Participants were asked, "Have you experienced any of the following (listed) symptoms over the last week?" ( $0=$ no, $1=$ yes), and if so, "How severe was the symptom?" ( 1 = mild, 2 = moderate, 3 =severe $)$ and, "How much did the symptom bother you?" ( $1=$ not at all, $2=$ a little, $3=$ quite a bit, 4 =very much). For this study, one item (relating to nausea following treatment) was dropped, reducing the scale to 23 items. The C-SAS shows acceptable levels of validity and reliability (Cronbach's $\alpha, 0.75$ ), as well as responsiveness to clinical change. ${ }^{17}$

\section{Statistical analysis}

Descriptive statistics were obtained for each of the demographic, treatment and disease variables as well as physical symptom prevalence, severity, symptom distress (bother), anxiety and depression scores. To explore how symptom distress scores clustered together, a series of exploratory factor analyses (FAs) and principal components analyses (PCAs) were conducted until a clinically meaningful solution was found. ${ }^{21,22}$ FAs and PCAs are statistical techniques applied to a set of observed variables to investigate whether they form relatively independent subsets or factors. Factors are latent variables interpreted to be responsible for the pattern of correlations among observed variables. To assist interpretation, factors are mathematically rotated, helping to separate the factors into a simple structure (ie, variables only load on one factor, and each factor only has some variables load on it). If the factors are correlated, then an oblique rotation yields the best solution; conversely, uncorrelated factors are best interpreted by applying orthogonal rotations. In explorative FAs and PCAs, a series of runs employing different methods of extraction and rotations is conducted until a good solution is found and a simple structure is achieved. $^{21,22}$ To maintain a sample size large enough for the analysis, patients reporting no prevalence of the symptom were given a score of zero. In the final solution, maximum likelihood extraction with direct oblimin rotation $($ delta $=0)$ with Kaiser normalisation was found to yield the most sensible solution. Factor loadings of $\geqslant 0.40$ were considered for interpretation of a factor (explaining 16\% of variance or greater). This value has been reported as best for interpretative purposes. ${ }^{23}$

To investigate the relationship between physical symptom distress, depression and anxiety, two separate hierarchical regressions were conducted; one with depression and one with anxiety as the dependent variable. Discrete variables were dummy coded for the analysis. To ensure there were no empty cells in the multiple regression equation for breast cancer by sex, cancer site was dummy coded by sex, creating five variables. Age, cancer site by sex, cancer stage, and previous cancer treatment status were entered initially into the equation. Excluding the contribution of two items

\section{Prevalence of symptoms, anxiety, depression, and of significant symptom severity and symptom bother in 192 patients before chemotherapy for breast or gastrointestinal cancers or lymphoma}

\begin{tabular}{|c|c|c|c|}
\hline \multirow[b]{2}{*}{ Symptom } & \multirow[b]{2}{*}{ Prevalence } & \multicolumn{2}{|c|}{$\begin{array}{l}\text { Chemotherapy Symptom } \\
\text { Assessment Scale rating }\end{array}$} \\
\hline & & $\begin{array}{c}\text { Symptom severity } \\
\text { (moderate or } \\
\text { severe) }\end{array}$ & $\begin{array}{l}\text { Symptom bother } \\
\text { (quite a bit or } \\
\text { very much) }\end{array}$ \\
\hline Nausea & $42(22 \%)$ & $11(6 \%)$ & $30(16 \%)$ \\
\hline Vomiting & $14(7 \%)$ & $6(3 \%)$ & $11(6 \%)$ \\
\hline Constipation & $44(23 \%)$ & $22(11 \%)$ & $34(18 \%)$ \\
\hline Diarrhoea & 27 (14\%) & $12(6 \%)$ & $21(11 \%)$ \\
\hline Pain & 93 (48\%) & $53(28 \%)$ & 75 (39\%) \\
\hline Shortness of breath & $38(20 \%)$ & $17(9 \%)$ & $29(15 \%)$ \\
\hline Signs of infection & $28(15 \%)$ & $9(5 \%)$ & $22(12 \%)$ \\
\hline Bleeding/bruising & $35(18 \%)$ & $20(10 \%)$ & $21(11 \%)$ \\
\hline Pins and needles/numbness & $41(21 \%)$ & $9(5 \%)$ & 19 (10\%) \\
\hline Skin or nail problems & $24(13 \%)$ & $8(4 \%)$ & $2(1 \%)$ \\
\hline Hair loss & $2(1 \%)$ & $1(1 \%)$ & $1(1 \%)$ \\
\hline Mouth/throat problems & $24(13 \%)$ & $9(5 \%)$ & $6(3 \%)$ \\
\hline Changes to appetite/taste & $39(20 \%)$ & $23(12 \%)$ & $6(3 \%)$ \\
\hline Weight loss/gain & $49(26 \%)$ & $15(8 \%)$ & $7(4 \%)$ \\
\hline Eye problems & $15(8 \%)$ & $6(3 \%)$ & $2(1 \%)$ \\
\hline Feeling weak & 57 (30\%) & $25(13 \%)$ & $15(8 \%)$ \\
\hline Feeling unusually tired & $87(45 \%)$ & $36(19 \%)$ & 19 (10\%) \\
\hline Difficulty sleeping & $86(45 \%)$ & $50(26 \%)$ & $21(11 \%)$ \\
\hline Headaches & $42(22 \%)$ & $19(10 \%)$ & $5(3 \%)$ \\
\hline Feeling anxious/worried & $132(69 \%)$ & $65(34 \%)$ & $35(18 \%)$ \\
\hline Feeling low/depressed & $72(38 \%)$ & $28(15 \%)$ & $21(11 \%)$ \\
\hline Changes to sexual relationships & $46(24 \%)$ & $28(15 \%)$ & $9(5 \%)$ \\
\hline Changes to period & $12(6 \%)$ & $6(3 \%)$ & $1(1 \%)$ \\
\hline \multicolumn{4}{|c|}{ Hospital Anxiety and Depression Scale scores } \\
\hline Score $\geqslant 8$ on the anxiety scale & $45 \%$ & na & na \\
\hline Score $\geqslant 8$ on the depression scale & $25 \%$ & na & na \\
\hline
\end{tabular}


directly related to measuring anxiety (feeling anxious or worried) and depression (feeling low or depressed), weighted factor scores were calculated for physical cluster symptoms and were entered into the separate equations as the second step. Significance levels were set at 0.05 .

\section{RESULTS}

\section{Participant profile}

Of 247 patients approached about the study, 192 (78\%) consented to participate. Fortytwo patients declined to participate; 29 (69\%) said they were not interested in the study and the remaining 13 patients (31\%) said they felt too anxious. An additional 13 patients did not return the study consent form and baseline questionnaire before commencing their chemotherapy and were excluded from the analysis. Of the 192 consenting patients, 83 (43\%) had breast cancer, 57 (30\%) had cancer of the GI tract (colorectal, 39; gastro-oesophageal, 11; pancreatic, 5; and hepatobiliary, 2) and 52 (27\%) had lymphoma (Hodgkin's disease, 11; non-Hodgkin's disease, 41). The average age of participants was 52.4 years (SD, 12.8; range, 20-83 years) and most were female (125, 65\%). Most participants were not working $(113,59 \%)$, spoke English as a first language $(169,88 \%)$, and were married (135, 70\%).

A total of 32 participants (17\%) were diagnosed with stage I disease (breast cancer, 16; GI cancer, 3; lymphoma, 13), 54 (28\%) with stage II disease (breast cancer, 32; GI cancer, 10; lymphoma, 12), 74 (39\%) with stage III disease (breast cancer, 30; GI cancer, 33; lymphoma, 11) and 32 (17\%) had stage IV disease (breast cancer, 5; GI cancer, 11; lymphoma, 16). ECOG scores were $0(130,68 \%), 1(50,26 \%)$ and 2 (8, $4 \%)$. One-hundred and eight participants (56\%) had either surgery or radiotherapy before this chemotherapy treatment. The remainder had received no previous treatment for their cancer. On average, patients completed study measures 10.5 days (SD, 8.2; range, 1-50 days) before commencing chemotherapy.

\section{Prevalence of anxiety, depression and physical symptoms}

Eighty-seven participants (45.3\%) reported elevated anxiety scores and 48 (25.0\%) reported elevated depression scores (ie, HADS subscale scores $\geqslant 8$; Box 1 ). Participants reported pain, tiredness and difficulty sleeping as the most prevalent physical

\section{Exploratory factor analysis investigating the clustering of symptom distress scores with a five-factor solution for 192 patients before chemotherapy for breast or gastrointestinal cancers or lymphoma}

\begin{tabular}{|c|c|c|c|c|c|}
\hline \multirow[b]{2}{*}{ Symptom } & \multicolumn{5}{|c|}{ Symptom cluster } \\
\hline & $\begin{array}{l}\text { Nutritional } \\
\text { (Factor 1) }\end{array}$ & $\begin{array}{l}\text { Malaise } \\
\text { (Factor 2) }\end{array}$ & $\begin{array}{c}\text { Gastro- } \\
\text { intestinal } \\
\text { (Factor 3) }\end{array}$ & $\begin{array}{l}\text { Emotional } \\
\text { (Factor 4) }\end{array}$ & $\begin{array}{r}\text { General } \\
\text { physical } \\
\text { (Factor 5) }\end{array}$ \\
\hline Changes to appetite & 0.895 & 0.049 & 0.091 & -0.041 & -0.013 \\
\hline Weight loss/gain & 0.466 & 0.098 & 0.062 & -0.002 & 0.065 \\
\hline Diarrhoea & 0.304 & -0.029 & -0.049 & 0.028 & -0.014 \\
\hline Feeling unusually tired & 0.061 & 0.612 & 0.095 & -0.094 & 0.242 \\
\hline Feeling weak & 0.143 & 0.592 & 0.058 & -0.079 & 0.251 \\
\hline Headaches & 0.032 & 0.472 & -0.005 & 0.016 & -0.058 \\
\hline Difficulty sleeping & -0.041 & 0.355 & 0.100 & -0.301 & -0.091 \\
\hline Vomiting & -0.102 & -0.107 & 0.880 & 0.082 & -0.044 \\
\hline Nausea & 0.127 & -0.096 & 0.686 & -0.015 & 0.058 \\
\hline Pain & -0.026 & 0.266 & 0.424 & -0.004 & 0.080 \\
\hline Constipation & 0.038 & 0.072 & 0.351 & -0.004 & -0.039 \\
\hline Feeling low/depressed & 0.052 & 0.119 & -0.066 & -0.746 & 0.030 \\
\hline Feeling anxious/worried & -0.018 & 0.172 & -0.056 & -0.695 & -0.031 \\
\hline Changes to sexual relationships & -0.031 & -0.115 & 0.008 & -0.349 & 0.025 \\
\hline Mouth/throat problems & 0.093 & -0.111 & 0.009 & -0.025 & 0.618 \\
\hline Shortness of breath & 0.103 & 0.070 & 0.025 & -0.077 & 0.553 \\
\hline Signs of infection & 0.109 & 0.039 & 0.194 & -0.145 & 0.378 \\
\hline Eye problems & -0.078 & -0.026 & -0.082 & 0.012 & 0.362 \\
\hline Pins and needles/numbness & -0.107 & 0.287 & -0.075 & -0.010 & 0.361 \\
\hline Skin/nail problems & 0.071 & -0.029 & 0.165 & -0.046 & 0.349 \\
\hline Bleeding/bruising & -0.005 & 0.138 & 0.020 & 0.140 & 0.314 \\
\hline Variance explained (total 36.7\%) & $14.5 \%$ & $9.0 \%$ & $4.8 \%$ & $5.3 \%$ & $3.1 \%$ \\
\hline
\end{tabular}

Rotation method: oblimin with Kaiser normalisation. Rotation converged in 8 iterations. Factor loadings $\geqslant 0.40$ are shown in bold.

symptoms, with pain, difficulty sleeping and feeling unusually tired as their most severe symptoms. The three most bothersome physical symptoms were pain, constipation and nausea. Emotional symptoms were also prevalent, as measured by the C-SAS.

\section{Symptom clusters}

Two of the 23 symptoms listed in Box 1 were excluded from the factor analysis "Hair loss" (because it was reported by only two people), and "Changes to [menstrual] period" (because it was sex-specific). A five-factor solution was extracted, explaining $36.7 \%$ of total variance (Box 2). No cross-loadings of symptoms onto multiple factors were detected at a factor loading of 0.40 .

Review of items loading at 0.40 or greater on one of the five factors suggested groupings of items measuring nutritional symptoms, general malaise symptoms, gas- trointestinal symptoms, emotional symptoms, and general physical symptoms, respectively. Cronbach's $\alpha$ for the five factors were $0.65,0.69,0.65,0.65$ and 0.58 , respectively.

\section{Regression analyses}

After controlling for age, sex, cancer site, cancer stage, and previous cancer treatment (Box 3), the combination of all physical symptom clusters accounted for $22 \%$ of the variance of depression and $7 \%$ of the variance of anxiety. "General malaise", "nutritional" and "gastrointestinal" symptom clusters made a significant independent contribution to the prediction of depression (Box 3). However, together, symptom clusters did not significantly contribute to the explained variance of anxiety after accounting for covariates. Inspection of the unstandardised regression coefficient $(\beta)$ weights for 


\begin{tabular}{|c|c|c|c|c|c|c|c|}
\hline $\begin{array}{l}3 \text { Summary of hier } \\
\text { cancer site, stac } \\
\text { cancers or lymp }\end{array}$ & $\begin{array}{l}\text { rarchical regressions investi } \\
\text { ge and physical symptom cl } \\
\text { homa }\end{array}$ & $\begin{array}{l}\text { pred } \\
\text { in } 19\end{array}$ & $\begin{array}{l}\text { rs of depress } \\
\text { atients befo }\end{array}$ & $\begin{array}{l}\text { ind an } \\
\text { emoth }\end{array}$ & , inclu & $\begin{array}{l}\text { age, previo } \\
\text { st or gastroi }\end{array}$ & $\begin{array}{l}\text { eatmen } \\
\text { tinal }\end{array}$ \\
\hline & & & Model 1 & & & Model 2 & \\
\hline Dependent variable & Independent variable & $\beta$ & $95 \% \mathrm{Cl}$ for $\beta$ & $t$ & $\beta$ & $95 \% \mathrm{Cl}$ for $\beta$ & $t$ \\
\hline Depression & Age & 0.02 & -0.02 to 0.06 & 0.94 & 0.02 & -0.02 to 0.06 & 1.05 \\
\hline & Previous cancer treatment & -0.27 & -1.62 to 1.08 & -0.39 & -0.60 & -1.82 to 0.61 & -0.98 \\
\hline & Cancer site & & & & & & \\
\hline & Male lymphatic system & 0.25 & -1.67 to 2.16 & 0.26 & 0.80 & -0.96 to 2.56 & 0.90 \\
\hline & Male gastrointestinal tract & -0.11 & -1.74 to 1.53 & -0.13 & -0.17 & -1.65 to 1.31 & -0.22 \\
\hline & Female lymphatic system & 0.57 & -1.36 to 2.49 & 0.58 & 0.29 & -1.51 to 2.08 & 0.32 \\
\hline & Female gastrointestinal tract & 0.68 & -1.31 to 2.67 & 0.68 & -0.39 & -2.20 to 1.42 & -0.43 \\
\hline & Female breast* & - & - & - & - & - & - \\
\hline & Clinical stage of cancer & & & & & & \\
\hline & । & 0.42 & -1.42 to 2.25 & 0.45 & 0.66 & -0.98 to 2.31 & 0.79 \\
\hline & $\|$ & 0.57 & -1.11 to 2.26 & 0.67 & 1.13 & -0.41 to 2.67 & 1.45 \\
\hline & III & 0.47 & -1.11 to 2.04 & 0.58 & 0.72 & -0.70 to 2.15 & 1.01 \\
\hline & $\mathrm{IV}^{*}$ & - & - & - & - & - & - \\
\hline & Physical symptom cluster & & & & & & \\
\hline & Nutritional & & & & 0.70 & 0.16 to 1.24 & $2.57^{\dagger}$ \\
\hline & General malaise & & & & 1.46 & 0.81 to 2.12 & $4.39^{\ddagger}$ \\
\hline & Gastrointestinal & & & & 0.73 & 0.14 to 1.32 & $2.45^{\dagger}$ \\
\hline & General physical & & & & -0.63 & -1.30 to 0.04 & -1.86 \\
\hline$R^{2}$ change & & & & 0.01 & & & 0.22 \\
\hline F change & & & & 0.24 & & & $12.14^{\ddagger}$ \\
\hline Anxiety & Age & -0.02 & -0.07 to 0.03 & -0.91 & 0.02 & -0.07 to 0.03 & -0.66 \\
\hline & Previous cancer treatment & -0.40 & -1.93 to 1.12 & -0.52 & -0.66 & -2.15 to 0.83 & -0.87 \\
\hline & Cancer site & & & & & & \\
\hline & Male lymphatic system & 0.45 & -1.71 to 2.60 & 0.41 & 0.73 & -1.42 to 2.87 & 0.67 \\
\hline & Male gastrointestinal tract & -0.90 & -2.75 to 0.94 & -0.96 & -0.84 & -2.65 to 0.97 & -0.92 \\
\hline & Female lymphatic system & -0.53 & -2.69 to 1.64 & -0.48 & 0.79 & -2.98 to 1.41 & -0.71 \\
\hline & Female gastrointestinal tract & -0.81 & -3.04 to 1.43 & -0.71 & -1.51 & -3.72 to 0.70 & -1.35 \\
\hline & Female breast* & - & - & & - & - & - \\
\hline & Clinical stage of cancer & & & & & & \\
\hline & । & 0.31 & -1.75 to 2.37 & 0.30 & 0.35 & -1.67 to 2.36 & 0.34 \\
\hline & $\|$ & 0.02 & -1.88 to 1.91 & 0.02 & 0.14 & -1.74 to 2.01 & 0.14 \\
\hline & III & 1.35 & -0.43 to 3.11 & 1.50 & 1.37 & -0.37 to 3.11 & 1.56 \\
\hline & $\mathrm{IV}^{*}$ & - & - & - & - & - & - \\
\hline & Physical symptom cluster & & & & & & \\
\hline & Nutritional & & & & 0.55 & -0.11 to 1.21 & 1.64 \\
\hline & General malaise & & & & 1.27 & 0.46 to 2.07 & $3.11^{\S}$ \\
\hline & Gastrointestinal & & & & -0.10 & -0.82 to 0.63 & -0.26 \\
\hline & General physical & & & & -0.36 & -1.17 to 0.46 & -0.86 \\
\hline$R^{2}$ change & & & & 0.04 & & & 0.07 \\
\hline F change & & & & 0.78 & & & 3.66 \\
\hline
\end{tabular}

factors contributing to anxiety may suggest that "general malaise" did uniquely contribute to some of the explained variance for anxiety.

\section{DISCUSSION}

Our findings support previous studies identifying high levels of anxiety and depression in patients prior to commencing chemotherapy. In addition, physical symptoms were also prevalent and occurred in groups similar to previously identified clusters of cancer symptoms. ${ }^{4,24}$ Further, many 
symptoms were also reported as distressing. The prevalence of physical symptoms and resulting symptom distress was unexpected, as patients completed study measures before the commencement of chemotherapy, and had been diagnosed with potentially curative disease. The presence of pain in almost half of the sample is most likely to be linked with previous surgery rather than the cancer itself. Our study supports previous findings that symptom burden, patient functional impairment, and tiredness independently predict depression. ${ }^{11}$ More specifically, we identified that particular symptom clusters may predict depression (malaise, nutrition, gastrointestinal). While the regression results also indicated that the malaise factor may also uniquely contribute to patient anxiety, caution should be used when interpreting these findings as this factor alone explained only a small proportion of the variance.

We used the HADS in this study because it does not explicitly assess the somatic aspects of depression and anxiety. This is important because of the potential association between these somatic symptoms and having cancer. The Diagnostic and statistical manual of mental disorders, fourth edition (DSM-IV) defines nine symptoms that are indicative of depression, of which two are important in this context: (i) significant weight loss when not dieting, or weight gain, or change in appetite; and (ii) fatigue or loss of energy. ${ }^{25}$ In our sample, these symptoms are found in the nutritional and malaise symptom clusters, which were found to be predictive of higher depression scores. Hence, it is difficult to separate whether or not patients are experiencing these symptoms because of the cancer or because they are experiencing some level of depression. Alternatively, a common underlying biological mechanism may be responsible for these symptoms occurring simultaneously, such as an inflammatory response in which cytokines have previously been implicated. ${ }^{4}$

Similarly, for anxiety, the DSM-IV defines six symptoms in conjunction with feelings of anxiety or worries, one of which (tires easily) is contained within the malaise symptom cluster. Disentangling the causal direction of the relationship between these physical symptoms and psychological distress is therefore difficult, if not impossible. However, we suggest anxiety and depression is too narrow a construct to understand the distress associated with commencing cancer treatment. Further research to explore the construct of distress and its measurement in patients with cancer is required. This is supported by our finding that the prevalence of anxiety and depression, as detected by the HADS, was lower than for those single-item questions on the C-SAS that measure "feeling anxious/worried" and "feeling low/depressed". This may suggest that the specific constructs measured by the two methods differ, with the C-SAS questions tapping into a broader definition of patient distress that may be more related to the somatic aspects of anxiety and depression.

The high levels of symptoms reported in this study support the routine screening of patients about to commence chemotherapy for a range of common physical and emotional needs. Although needs-screening is recommended, ${ }^{26-28}$ it is rarely routinely practised. Additionally, clinicians experience difficulty in accurately identifying anxiety and depression, ${ }^{29,30}$ emphasising the need to refine our knowledge of symptoms and distress in clinical assessment to ensure that at-risk patients are identified.

Although we sampled patients with three highly prevalent groups of tumours in this study, caution should be applied in generalising our findings beyond these three groups. We used a cross-sectional design, and so we cannot definitively indicate causality. However, our findings do contribute to the body of evidence about the interrelationship between physical and emotional distress, and indicate directions for future research in terms of the need for greater clarity about the construct of distress in the cancer population. Our inclusion of prevalence, severity and distress (ie, the extent to which a particular symptom affects the life of individual patients) is in line with the emerging definition of symptom burden, and how this should be used as a measure in the clinical setting. ${ }^{4,13,17}$ Further work to refine the construct of burden and its relationship to distress is also required.

Two important clinical implications arise from our research. First, we recommend that all patients entering chemotherapy should be screened for both physical and psychological needs, even when the apparent disease burden is low. Second, we recommend that routine screening and assessment data be used to help identify the most important areas for intervention development and testing in patients entering chemotherapy to enhance our ability to improve supportive care outcomes.

\section{ACKNOWLEDGEMENTS}

Funding from both the National Health and Medical Research Council (NHMRC) and the Leukaemia Foundation made the completion of this project possible.

\section{COMPETING INTERESTS}

None identified.

\section{AUTHOR DETAILS}

Sibilah J Breen, BSc(Hons), PhD, Research Fellow, Nursing and Supportive Care Research ${ }^{1}$ Carl M Baravelli, BBSc(Hons), Supportive Care Researcher, Nursing and Supportive Care Research ${ }^{1}$

Penelope E Schofield, BSc(Hons), PhD,

Strategic Director of Research and

Development, Nursing and Supportive Care

Research $^{1}$

Michael Jefford, MPH, PhD, FRACP, Medical Oncologist, Department of Haematology and Medical Oncology ${ }^{1}$

Patsy M Yates, RN, MSocSci, PhD, Professor of Nursing ${ }^{2}$

Sanchia K Aranda, BApplSci(AdvNurs), MN, $\mathrm{PhD}$, Director, Nursing and Supportive Care Research

1 Peter MacCallum Cancer Centre, Melbourne, $\mathrm{VIC}$.

2 Queensland University of Technology,

Brisbane, QLD.

Correspondence:

sibilah.breen@petermac.org

\section{REFERENCES}

1 Zabora J, BrintzenhofeSzoc K, Curbow B, et al. The prevalence of psychological distress by cancer site. Psychooncology 2001; 10: 19-28.

2 Spiegel D. Cancer and depression. Br J Psychiatry 1996; 168 (30 Suppl): 109-116.

3 Kissane DW, Clarke DM, Ikin J, et al. Psychological morbidity and quality of life in Australian women with early-stage breast cancer: a crosssectional survey. Med J Aust 1998; 169: 192196.

4 Cleeland CS. Symptom burden: multiple symptoms and their impact as patient-reported outcomes. J Natl Cancer Inst Monogr 2007; (37): 16-21.

5 Tiernan E. Depression in terminally ill cancer patients. Ir Med J 1998; 91: 47-48.

6 DiMatteo MR, Lepper HS, Croghan TW. Depression is a risk factor for noncompliance with medical treatment: meta-analysis of the effects of anxiety and depression on patient adherence. Arch Intern Med 2000; 160: 2101 2107.

7 Creed F, Morgan R, Fiddler M, et al. Depression and anxiety impair health-related quality of life and are associated with increased costs in general medical inpatients. Psychosomatics 2002; 43: 302-309.

8 Colleoni M, Mandala M, Peruzzotti G, et al. Depression and degree of acceptance of adjuvant cytotoxic drugs. Lancet 2000; 356: 1326 1327. 
9 Koenig HG, Shelp F, Goli V, et al. Survival and health care utilization in elderly medical inpatients with major depression. J Am Geriatr Soc 1989; 37: 599-606.

10 Paice JA. Assessment of symptom clusters in people with cancer. J Natl Cancer Inst Monogr 2004; (32): 98-102.

11 Hopwood P, Stephens RJ. Depression in patients with lung cancer: prevalence and risk factors derived from quality-of-life data. J Clin Oncol 2000; 18: 893-903.

12 Lethborg C, Aranda S, Cox S, et al. To what extent does meaning mediate adaptation to cancer? The relationship between physical suffering, meaning in life, and connection to others in adjustment to cancer. Palliat Support Care 2007; 5: 377-388.

13 Kirkova J, Davis MP, Walsh D, et al. Cancer symptom assessment instruments: a systematic review. J Clin Oncol 2006; 24: 1459-1473.

14 Hargraves M, Yates P, Grove K, et al. Commencing adjuvant chemotherapy for early breast cancer: what should nursing assessment involve? Oncol Nurs Forum 2004; 31: 388.

15 Wedding U, Koch A, Rohrig B, et al. Depression and functional impairment independently contribute to decreased quality of life in cancer patients before chemotherapy. Acta Oncol 2008; 47: 56-62.

16 Given B, Given CW, Sikorskii A, et al. Establishing mild, moderate, and severe scores for cancer-related symptoms: how consistent and clinically meaningful are interference-based severity cut-points? J Pain Symptom Manage 2008; 35: 126-135.

17 Brown V, Sitzia J, Richardson A, et al. The development of the Chemotherapy Symptom Assessment Scale (C-SAS): a scale for the routine clinical assessment of the symptom experiences of patients receiving cytotoxic chemotherapy. Int J Nurs Stud 2001; 38: 497510.

18 Zigmond AS, Snaith RP. The Hospital Anxiety and Depression Scale. Acta Psychiatr Scand 1983; 67: 361-370.

19 Moorey S, Greer S, Watson M, et al. The factor structure and factor stability of the Hospital Anxiety and Depression Scale in patients with cancer. Br J Psychiatry 1991; 158: 255-259.

20 Holtom N, Barraclough J. Is the Hospital Anxiety and Depression Scale (HADS) useful in assessing depression in palliative care? Palliat Med 2000; 14: 219-220.

21 Tabachnick BG, Fidell LS. Using multivariate statistics. New York: HarperCollins, 1996: 635709.

22 Pett MA, Lackey NR, Sullivan JJ. Making sense of factor analysis: the use of factor analysis for instrument development in health care research. Thousand Oaks, Calif: Sage Publications, 2003.

23 Stevens JP. Applied multivariate statistics for the social sciences. 2nd ed. Hillsdale, NJ: Lawrence Erlbaum Associates, 1992: 370-372.

24 Chen ML, Tseng HC. Symptom clusters in cancer patients. Support Care Cancer 2006; 14: 825-830.
25 American Psychiatric Association. DSM-IV. Diagnostic and statistical manual of mental disorders. 4th ed. Washington, DC: American Psychiatric Association Press, 1994.

26 National Comprehensive Cancer Network. Clinical practice guidelines in oncology. Distress management. V.1.2008. http:// www.nccn.org/professionals/physician_gls/ PDF/distress.pdf (accessed Mar 2009).

27 National Institute for Clinical Excellence. Guidance on cancer services. Improving supportive and palliative care for adults with cancer. The manual. London: NICE, 2004. http:// www.nice.org.uk/nicemedia/pdf/csgspmanual.pdf (accessed Mar 2009).

28 National Breast Cancer Centre and National Cancer Control Initiative. Clinical practice guidelines for the psychosocial care of adults with cancer. Sydney: NBCC, 2003.

29 Fallowfield L, Ratcliffe D, Jenkins V, et al. Psychiatric morbidity and its recognition by doctors in patients with cancer. Br J Cancer 2001; 84: 1011-1015.

30 Newell S, Sanson-Fisher RW, Girgis A, et al. How well do medical oncologists' perceptions reflect their patients' reported physical and psychosocial problems? Data from a survey of five oncologists. Cancer 1998; 83: 1640-1651.

(Received 31 Jul 2008, accepted 12 Feb 2009) 